\title{
Increased vascular endothelial growth factor in acute eosinophilic pneumonia
}

\author{
Y. Nishigaki*, S. Fujiuchi*, Y. Yamazaki*, H. Matsumoto*, A. Takeda*, Y. Fujita*, K. Okamoto*, \\ T. Fujikane*, T. Shimizu*, K. Kikuchi\#
}

Increased vascular endothelial growth factor in acute eosinophilic pneumonia. Y. Nishigaki, S. Fujiuchi, Y. Yamazaki, H. Matsumoto, A. Takeda, Y. Fujita, K. Okamoto, T. Fujikane, T. Shimizu, K. Kikuchi. (C)ERS Journals Ltd 2003.

ABSTRACT: Acute eosinophilic pneumonia (AEP) is associated with the presence of diffuse pulmonary infiltrates on the chest radiograph and an increased number of eosinophils and an elevation of interleukin (IL)-5 levels in bronchoalveolar lavage (BAL) fluid. Vascular endothelial growth factor (VEGF) is a constitutively expressed protein encoded by messenger ribonucleic acid in human eosinophils and is released following stimulation with IL-5. However, the roles of IL-5 and VEGF in the pathogenesis or activity of this disease have not been clarified.

The authors investigated the cells and the levels of these two factors in BAL fluid in five AEP patients and five normal controls before and after corticosteroid treatment.

The absolute number of eosinophils $\cdot \mathrm{mL}^{-1}$, IL-5 and VEGF levels in patients before treatment were higher than in controls $\left(53.8\right.$ versus $0.3 \times 10^{4} \cdot \mathrm{mL}^{-1}, 490.1$ versus $5.2 \mathrm{pg} \cdot \mathrm{mL}^{-1}$ and 643.0 versus $133.9 \mathrm{pg} \cdot \mathrm{mL}^{-1}$, respectively). IL-5 and VEGF rapidly decreased to the control level in parallel with clinical improvement. The relationship between eosinophilia and IL-5 and VEGF levels was strongly significant.

Elevated interleukin-5 in the lung may initiate the recruitment of eosinophils and enhance the release of mediators, such as vascular endothelial growth factor from eosinophils, which, in turn, increases the permeability of blood vessels.

Eur Respir J 2003; 21: 774-778.
*Dept of Respiratory Medicine, National Dohoku Hospital, and ${ }^{\#}$ The First Dept of Internal Medicine, Asahikawa Medical College, Asahikawa, Japan.

Correspondence: Y. Nishigaki

Dept of Respiratory Medicine

National Dohoku Hospital

7 Hanasaki

Asahikawa 078-8644

Japan

Fax: 81166539184

E-mail: n.yhsoraroukou@gaea.ocn. ne.jp

Keywords: Acute eosinophilic pneumonia bronchoalveolar lavage interleukin-5

vascular endothelial growth factor

Received: September 172002

Accepted: December 82002
Acute eosinophilic pneumonia (AEP) is characterised by an acute febrile illness and severe hypoxaemia, associated with the presence of diffuse pulmonary infiltrates on the chest radiograph and an increased number of eosinophils in bronchoalveolar lavage (BAL) and/or lung biopsy specimens [1-3]. The number of reports describing AEP cases has recently increased and several of these have demonstrated elevation of interleukin (IL)-5 levels in serum and BAL fluid [4-6].

IL-5 is very important among the eosinophil-related cytokines because of its selective function of eosinophil activation and recruitment $[7,8]$, and is produced mainly by $\mathrm{T}$-helper lymphocytes $[9,10]$.

The major findings on high-resolution computed tomography included peripheral ground-glass opacities distributed along pulmonary veins as well as along bronchovascular bundles, thickened interlobular septa, and pleural effusion $[11,12]$. These resemble photographic findings of pulmonary oedema. In the histopathological findings of AEP, BUCHHEIT et al. [3] reported that numerous intra-alveolar and interstitial eosinophils as well as diffuse alveolar oedema were present [3]. Vascular endothelial growth factor (VEGF), also known as vascular permeability factor, is a potent, multifunctional cytokine that exerts several important actions on the vascular endothelium $[13,14]$. Human eosinophils constitutively transcribe messenger ribonucleic acid (mRNA), encoding VEGF, and store the protein product, releasing it following stimulation with granulocyte-macrophage colony-stimulating factor (GM-CSF) or IL-5 [15].

The authors hypothesised that activated T-helper lymphocytes produce IL-5 and, consequently, IL-5 leads to the persistent accumulation of eosinophils in the alveolar space, thus stimulating VEGF production by eosinophils. VEGF that is produced by eosinophils induces pulmonary oedema. In this study, the authors attempted to elucidate the relationship between eosinophilia and IL-5 and VEGF levels in AEP.

\section{Materials and methods}

\section{Subjects}

Five patients with acute eosinophilic pneumonia were seen in the Division between 1998-2001. Patients were selected for this study on the basis of clinical and pathological criteria. No patients suffered from organic disorders producing peripheral blood eosinophils, such as collagen diseases, allergic bronchopulmonary aspergillosis, sarcoidosis, Hodgkin's disease, hypereosinophilic syndrome, helminthic infections, or bacterial and mycotic infections with the exception of bronchial asthma.

The patients ranged in age from 18-58 yrs. Four of the patients were males and one was female. Five normal control subjects (four males and one female, aged 55-70 yrs) were also examined. All of the male subjects smoked cigarettes.

The symptoms at admission to the hospital were the presence of dyspnoea and respiratory failure, i.e. mean arterial oxygen tension $\left(\mathrm{Pa}_{2} \mathrm{O}_{2}\right)$ level was $7.6 \mathrm{kPa}$ (range $6.1-7.4 \mathrm{kPa}$; $57.1 \mathrm{mmHg}$, range $46.2-70.5 \mathrm{mmHg}$ ), mean arterial carbon dioxide tension level was $4.9 \mathrm{kPa}$ (range $3.4-5.6 ; 36.8 \mathrm{mmHg}$, range $25.4-42.0 \mathrm{mmHg}$ ) and the alveolar/arterial $\mathrm{Pa}, \mathrm{O}_{2}$ difference was $6.1 \mathrm{kPa}$ (range $3.6-7.8 \mathrm{kPa} ; 45.9 \mathrm{mmHg}$, range 
27.0-58.8 $\mathrm{mmHg}$ ). The patients underwent corticosteroid treatment and oxygen therapy, but none needed mechanical ventilation therapy.

\section{Bronchoalveolar lavage}

The first BAL was performed on the day of admission or the next day, using a flexible fibreoptic bronchoscope (Olympus BF p-30; Olympus, Tokyo, Japan) under local anaesthesia of the upper airway with $2 \%$ lidocaine. The bronchoscope was wedged into the subsegmental bronchus of the right middle lobe and $150 \mathrm{~mL}$ of normal saline were instilled in $50 \mathrm{~mL}$ aliquots. BAL fluid was filtered through sterile nylon mesh and centrifuged at $160 \times g$ for 2 min at $4^{\circ} \mathrm{C}$ to obtain the cell preparation. The cells were later stained using the MayGiemsa method and a differential count was performed on 200 cells. The remaining fluid was centrifuged at $500 \times g$ for 5 min and the supernatant was stored at $-80^{\circ} \mathrm{C}$ until used. Other specimens were used for flow cytometry to determine the CD4:CD8 ratio. Follow-up BAL was performed on days 10-29 after the first BAL when the clinical findings were improved.

\section{Determination of interleukin-5 and vascular endothelial growth factor}

IL-5 and VEGF were measured by a quantitative sandwich enzyme-linked immunosorbent assay, using antibodies recognising different epitopes of the cytokine molecules. The antibodies used for the assay of IL-5 (a monoclonal antihuman IL-5 capture antibody and a biotinylated monoclonal antihuman IL-5 detection antibody) were obtained from Endogen (Woburn, MA, USA). VEGF was measured using a VEGFspecific antibody (a polyclonal anti-VEGF capture antibody and a biotinylated monoclonal anti-VEGF detection antibody; R\&D Systems, Minneapolis, MN, USA). This assay predominantly binds the monomeric VEGF165 but also detects the VEGF isoform containing 121 amino acids. The assay utilised a capture antibody, a biotinylated detection antibody conjugated to streptavidin horseradish peroxidase, and colour development with tetramethylbenzidine/hydrogen peroxide. All assays were performed according to the protocol of the manufacturer. The detection limit was $30 \mathrm{pg} \cdot \mathrm{mL}^{-1}$ for IL-5 and $31.25 \mathrm{pg} \cdot \mathrm{mL}^{-1}$ for VEGF.

\section{Statistical analysis}

Data are expressed as mean \pm SEM. For the comparison of data measured before and after treatment, a Wilcoxonmatched paired test was used to determine statistical significance. The Mann-Whitney U-test was used for comparisons between AEP patients and control subjects. Correlation coefficients were calculated using Spearman's method. Values of $\mathrm{p}<0.05$ were considered significant.

\section{Results}

\section{Characteristics of bronchoalveolar lavage fluid cells}

The total number and differential count of leukocytes in BAL fluid are summarised in table 1. The total number of cells $\cdot \mathrm{mL}^{-1}$ in the BAL fluid of AEP patients before treatment was not higher than that after corticosteroid treatment, but was higher than that in normal control subjects $(p=0.0088)$. The percentage of eosinophils was $>20 \%(46.4 \pm 8.9 \%)$ before treatment. The absolute number of eosinophils $\cdot \mathrm{mL}^{-1}$ in the BAL fluid of AEP patients before treatment was higher than that in normal control subjects $(\mathrm{p}=0.0071)$, and this value decreased significantly after corticosteroid treatment $(\mathrm{p}=0.0431)$. The absolute number of eosinophils $\cdot \mathrm{mL}^{-1}$ in BAL fluid after treatment, however, was still higher than that in normal control subjects $(\mathrm{p}=0.0343)$. The CD4:CD8 ratio in the BAL fluid of AEP patients before treatment was higher than that in the controls $(\mathrm{p}=0.0283)$, and decreased to the level of the controls after corticosteroid treatment $(\mathrm{p}=0.0431)$.

\section{Interleukin-5 and vascular endothelial growth factor levels in bronchoalveolar lavage fluid}

IL-5 levels in the BAL fluid of the patients were elevated before treatment and decreased significantly after corticosteroid treatment: $490.1 \pm 151.2$ versus $6.9 \pm 2.7 \mathrm{pg} \cdot \mathrm{mL}^{-1}$ ( $\mathrm{p}=0.0431$; fig. 1a).

VEGF levels in the BAL fluid of the patients were also elevated before treatment and, again, decreased significantly

Table 1. - Characteristics of patients, total and differential counts in bronchoalveolar lavage (BAL) fluid

\begin{tabular}{|c|c|c|c|}
\hline & \multicolumn{2}{|c|}{ Patients with AEP } & \multirow[t]{2}{*}{ Normal controls } \\
\hline & Before treatment & After treatment & \\
\hline Age yrs & $29.8 \pm 7.2$ & & $60.4 \pm 2.9$ \\
\hline $\mathrm{M} / \mathrm{F}$ & $4 / 1$ & & $4 / 1$ \\
\hline \multicolumn{4}{|l|}{ Smoking history } \\
\hline Smoked & 4 & & 4 \\
\hline Exsmoker & 0 & & 0 \\
\hline Never smoked & 1 & & 1 \\
\hline Total cells $\times 10^{4} \cdot \mathrm{mL}^{-1}$ & $108.0 \pm 41.6^{\oplus}$ & $41.6 \pm 5.7$ & $28.0 \pm 2.5$ \\
\hline Macrophages $\%$ & $16.4 \pm 2.7$ & $54.8 \pm 8.9^{\#}$ & $83.6 \pm 2.4^{\top}$ \\
\hline Neutrophils \% & $13.0 \pm 7.7$ & $8.4 \pm 6.7$ & $8.6 \pm 3.1$ \\
\hline Lymphocytes \% & $24.2 \pm 6.0$ & $21 \pm 5.4$ & $9.4 \pm 3.1$ \\
\hline Eosinophils \% & $46.4 \pm 8.9^{\bullet}$ & $15.8 \pm 4.5^{\oplus}$ & $0.4 \pm 0.4$ \\
\hline Eosinophils $\times 10^{4} \cdot \mathrm{mL}^{-1}$ & $53.8 \pm 26.4^{\#, \oplus}$ & $6.3 \pm 2.2^{\circ}$ & $0.3 \pm 0.3$ \\
\hline CD4:CD8 ratio & $3.5 \pm 0.9^{\#, 9}$ & $1.2 \pm 0.2$ & $1.6 \pm 0.2$ \\
\hline
\end{tabular}

Data are presented as mean \pm SEM. Total cell counts and percentage of cells in BAL fluid from acute eosinophilic pneumonia (AEP) and normal control subjects. M: male; F: female. ${ }^{\#}: \mathrm{p}<0.05$ comparison of data measured before and after treatment in patients with AEP; ${ }^{\uparrow}: \mathrm{p}<0.05$ comparison between patients with AEP and control subjects. 

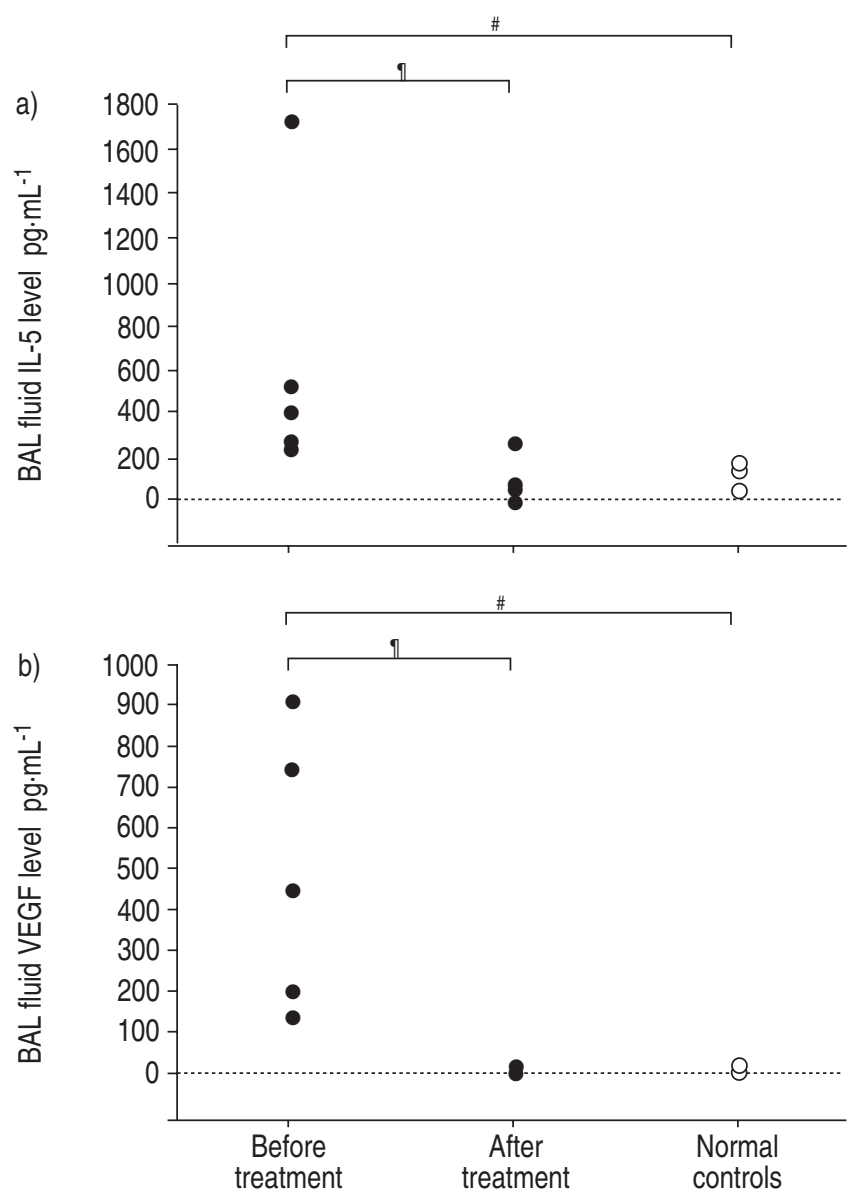

Fig. 1.-Concentrations of a) interleukin (IL)-5 and b) vascular endothelial growth factor (VEGF) in bronchoalveolar lavage (BAL) fluid obtained from acute eosinophilic pneumonia $(\bullet)$ patients, and normal controls $(\bigcirc)$, measured by enzyme-linked immunosorbent assay. The BAL fluid was obtained before and after corticosteroid treatment. ${ }^{\#}$ : $\mathrm{p}=0.009 ;{ }^{\circ}: \mathrm{p}=0.0431$.

after corticosteroid treatment: $643.0 \pm 281.0$ versus $148.1 \pm$ $56.8 \mathrm{pg} \cdot \mathrm{mL}^{-1}$ ( $\mathrm{p}=0.0431$; fig. 1b). IL-5 and VEGF levels in the BAL fluid of the patients were higher before treatment than in controls $\left(5.2 \pm 1.9 \mathrm{pg} \cdot \mathrm{mL}^{-1}\right.$ and $133.9 \pm 27.6 \mathrm{pg} \cdot \mathrm{mL}^{-1}$, respectively). IL-5 and VEGF levels in the BAL fluid of the patients after corticosteroid treatment decreased to the level in controls. Follow-up lavage was performed in all patients after treatment with corticosteroids and IL-5 was found to decrease in all cases. IL-5 was correlated with the absolute number of CD4+ lymphocytes $\cdot \mathrm{mL}^{-1}$ ( $\mathrm{p}=0.0194$; fig. $2 \mathrm{a}$ ).

The relationship between eosinophilia and IL-5 and VEGF levels in BAL fluid was strongly significant $(\mathrm{p}=0.0004$ and $\mathrm{p}<0.0001$, respectively; figs $2 \mathrm{~b}$ and $\mathrm{c}$ ), as was the relationship between IL-5 and VEGF levels ( $\mathrm{p}=0.0011$; fig. $2 \mathrm{~d}$ ).

\section{Discussion}

These data demonstrate that IL-5 and VEGF levels in BAL fluid are elevated in AEP and suggest that IL-5, which is produced mainly by T-helper lymphocytes, is probably produced in the lung. Elevated lung IL-5 may initiate the recruitment of eosinophils and enhance the release of mediators such as VEGF from eosinophils, which, in turn, increases the permeability of blood vessels.

AEP was first described in 1989 [1, 2] and is considered to represent a distinct clinical entity with the following diagnostic criteria: 1) acute febrile illness of $<5$ days duration; 2) hypoxaemic respiratory failure; 3) alveolar or alveolar/ interstitial chest radiographic opacity; 4) a BAL eosinophil level of $>25 \%$; 5) prompt and complete response to steroids without relapse on withdrawal; and 6) absence of parasitic, fungal, and other infections [16]. The number of reports describing AEP cases has recently increased and several of these have demonstrated the elevation of IL-5 levels in serum and BAL fluid [4-6]. Some reports have described the role of IL-5 in the pathogenesis or disease activity of AEP [4, 17]. IL-5 is particularly implicated in the development of eosinophilic inflammation, because it is involved in the promotion of the growth, maturation, migration, increased survival, recruitment, local infiltration, and activation of eosinophils, and enhances the release of mediators [7, 8, 18]. IL-5 is produced mainly by CD4+ T-helper lymphocytes $[9,10]$.

The major findings of high-resolution computed tomography at the height of the disease process in AEP include peripheral ground-glass opacities distributed along pulmonary veins as well as along bronchovascular bundles, thickened interlobular septa, and pleural effusion $[11,12]$. These resemble the photographic findings of pulmonary oedema. The histopathological findings of AEP demonstrate the presence of numerous intraalveolar and interstitial eosinophils and diffuse alveolar oedema, and the septa are free of fibrosis [3].

In this study, peripheral ground-glass opacities and airspace consolidation, thickened interlobular septa, and pleural effusion were found in all cases. Therefore, hypoxaemia and an increase in the alveolar/arterial $\mathrm{Pa}, \mathrm{O}_{2}$ difference was also present. The authors surmised that these conditions were caused from swelling of the alveolar interstitium with disturbances in the gas exchange.

Eosinophils are blood leukocytes that are recruited in helminthic infections and allergic diseases, especially bronchial asthma [19, 20]. Recent studies have shown that eosinophils synthesise a number of cytokines [21] that may contribute to the pathogenesis of asthma. VEGF is a potent, multifunctional cytokine that exerts several important actions on the vascular endothelium [13, 14]. VEGF was purified on the basis of its ability to induce transient vascular leakage and endothelial cell mitogenesis. It is a heparin-binding glycoprotein occurring in four molecular isoforms, generated by alternative splicing, which contain $121,165,189$ or 206 amino acids [22]. VEGF is produced by many cell types, including peripheral blood mononuclear cells [23].

The mRNA encodes for these splice variants in human peripheral blood mononuclear cells and eosinophils, as was demonstrated using reverse transcriptase-polymerase chain reaction (RT-PCR) and Southern hybridisation. RT-PCR of a mononuclear cell population demonstrated three alternatively spliced forms (VEGF121, VEGF165, VEGF189), as previously reported [23], while the analysis of eosinophilderived VEGF mRNA by RT-PCR yielded two amplification products, which were shown by Southern hybridisation to correspond to VEGF121 and VEGF165 [15]. The VEGFspecific antibody that was used in this assay predominantly binds VEGF165 but will also detect the VEGF isoform containing 121 amino acids.

The percentage of eosinophils and the absolute number of eosinophils $\cdot \mathrm{mL}^{-1}$, IL-5 and VEGF levels in the BAL fluid of AEP patients, were elevated before treatment and decreased significantly after treatment in parallel with clinical improvement. The relationship of the absolute number of eosinophils and IL-5 levels in the BAL fluid was strongly significant, as was the relationship of the absolute number of eosinophils and VEGF levels. These data suggest that eosinophils are strongly correlated with VEGF production in BAL fluid in AEP patients. 

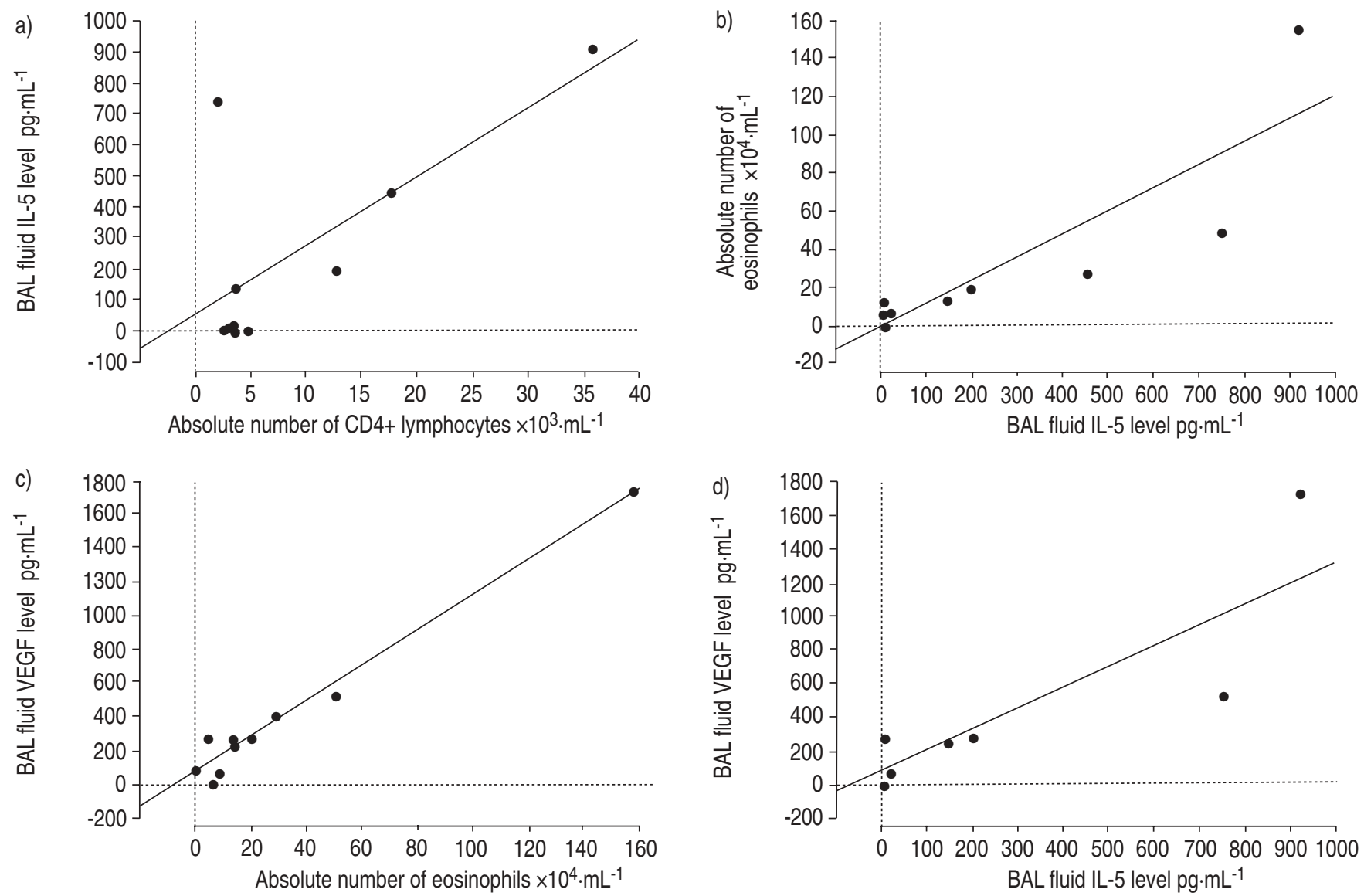

Fig. 2. -a) Interleukin (IL)-5 level in bronchoalveolar lavage (BAL) fluid correlated with the absolute number of $\mathrm{CD}^{4}+1 y m p h o c y t e s \cdot \mathrm{mL}^{-1}$ in BAL fluid from acute eosinophilic pneumonia (AEP) patients $\left(R^{2}=0.502, p=0.0194\right)$. The relationships between $\left.b\right)$ IL-5 level and absolute number of eosinophils in BAL fluid from AEP patients $\left(\mathrm{R}^{2}=0.762, \mathrm{p}=0.0004\right)$, c) absolute number of eosinophils and vascular endothelial growth factor (VEGF) level in BAL fluid from AEP patients $\left(\mathrm{R}^{2}=0.971, \mathrm{p}<0.0001\right)$, and $\left.\mathrm{d}\right)$ IL-5 and VEGF level in BAL fluid from AEP patients $\left(\mathrm{R}^{2}=0.714\right.$, $\mathrm{p}=0.0011)$ were all significant.

In humans, eosinophils have the capacity to generate VEGF, a vascular endothelial cell-specific cytokine that mediates angiogenesis and vascular permeability. Human eosinophils constitutively transcribe mRNA encoding VEGF, and store the product, probably in cytoplasmic granules, releasing it following stimulation with GM-CSF or IL-5. VEGF production by activated eosinophils at sites of allergic inflammation may contribute to vascular permeability and subsequent tissue oedema in patients with bronchial asthma [15].

Pulmonary oedema is defined as an excessive amount of extravascular water in the lungs [24]. The major consequence of pulmonary oedema is in the gas exchange units, where swelling of the alveolar interstitium and flooding of the alveoli cause disturbances in lung mechanical functions and gas exchange $[25,26]$. Although there are many causes of pulmonary oedema, the pathophysiology of pulmonary oedema can be generally classified as due to increased pressure or increased permeability [27, 28].

Permeability of pulmonary oedema is most commonly linked to local or systemic inflammatory processes, such as those associated with acute infection of the lung or systemic conditions including sepsis, the postoperative state, pancreatitis, burns, and trauma [27]. Overexpression of VEGF in the lung may be one mechanism of increased pulmonary vascular permeability in the early stages of acute lung injury [29]. Production by eosinophils of VEGF, which enhances vascular permeability, might contribute to the pulmonary oedema and disturbances in gas exchange in AEP.
It has been reported that AEP patients respond satisfactorily to steroids and become symptom-free with essentially normal respiratory function without relapse [16]. In the present study, the clinical symptoms of all patients promptly decreased and the photographic findings were improved, along with a decrease in the absolute number of eosinophils, IL-5 and VEGF levels in BAL fluid with glucocorticoid therapy.

The authors hypothesised that the decreases in eosinophils, IL-5 and VEGF levels were caused by the following: IL-5 synthesis by peripheral T-helper lymphocytes is inhibited by glucocorticoids, which has been demonstrated in vitro [30, 31]; eosinophils release the VEGF protein product following stimulation with GM-CSF or IL-5, a process sensitive to inhibition by glucocorticoids. Glucocorticoids both suppressed the VEGF product released from eosinophils and diminished the steady-state levels of eosinophil VEGF mRNA [15].

Although the percentage of eosinophils and the absolute number of eosinophils $\cdot \mathrm{mL}^{-1}$ in the BAL fluid of AEP patients did not decrease to the level of normal control subjects after corticosteroid treatment, IL-5 and VEGF levels rapidly returned to the control level in parallel with clinical improvement. The persistence of eosinophil accumulation in the alveolar space was considered to be caused by the increased survival of eosinophils due to IL-5, because the IL-5-induced prolongation of eosinophil survival persists for several weeks [7, 8]. 
The major findings of the present study were: 1) interleukin-5 could be recruited into the lung by eosinophils in acute eosinophilic pneumonia patients; and 2) a correlation was found between increased interleukin-5 and vascular endothelial growth factor levels and eosinophilia in bronchoalveolar lavage fluid. In conclusion, it has been demonstrated that vascular endothelial growth factor may play an important role in the pathogenesis of pulmonary oedema in patients with eosinophilic pneumonia.

\section{References}

1. Badesch DB, King TE Jr, Schwarz MI. Acute eosinophilic pneumonia: a hypersensitivity pneumonia? Am Rev Respir Dis 1989; 139: 249-252.

2. Allen JN, Pacht ER, Gadek JE, Davis WB. Acute eosinophilic pneumonia as a reversible cause of noninfectious respiratory failure. $N$ Engl $J$ Med 1989; 321: 569-574.

3. Buchheit J, Eid N, Rodgers G, Feger T, Yakoub O. Acute eosinophilic pneumonia with respiratory failure: a new syndrome? Am Rev Respir Dis 1992; 145: 716-718.

4. Okubo Y, Hossain M, Kai R. Adhesion molecules on eosinophils in acute eosinophilic pneumonia. Am J Respir Crit Care Med 1995; 151: 1259-1262.

5. Yamaguchi S, Okubo Y, Hossain M, et al. IL-5 predominant in bronchoalveolar lavage fluid and peripheral blood in a patient with acute eosinophilic pneumonia. Intern Med 1995; 34: 65-68.

6. Taniguchi H, Kadota J-I, Fujii T, et al. Activation of lymphocytes and increased interleukin-5 levels in bronchoalveolar lavage fluid in acute eosinophilic pneumonia. Eur Respir J 1999; 13: 217-220.

7. Lopez AF, Sanderson CJ, Gamble JR, Campbell HD, Young IG, Vadas MA. Recombinant human interleukin 5 is a selective activator of human eosinophil chemoattractant. J Exp Med 1988; 167: 219-224.

8. Wang JM, Rambaldi A, Biondi A, Chen ZG, Sanderson CJ, Mantovani A. Recombinant human interleukin 5 is a selective eosinophil chemoattractant. Eur J Immunol 1989; 19: 701-705.

9. Paul WE, Seder RA. Lymphocyte responses and cytokine. Cell 1994; 76: 241-251.

10. Mosmann TR, Sad S. The expanding universe of T-cell subsets: Th1, Th2 and more. Immunol Today 1996; 17: 143-147.

11. Mayo JR, Muller NL, Road J, Sisler J, Lillington G. Chronic eosinophilic pneumonia: CT findings in six cases. Am J Roentgenol 1989; 153: 727-730.

12. Tsunemi K, Kanayama I, Kondo T, Taniguti T, Ohta Y, Yanagimachi N. Acute eosinophilic pneumonia evaluated with high-resolution computed tomography. Intern Med 1993; 32: 891-894.

13. Dvorak HF, Brown LF, Detmar M, Dvorak AM. Vascular permeability factor/vascular endothelial growth factor, microvascular hyperpermeability, and angiogenesis. Am J Pathol 1995; 146: 1029-1039.

14. Thomas KA. Vascular endothelial growth factor, a potent and selective angiogenic agent. J Biol Chem 1996; 271: 603-606.
15. Horiuchi T, Weller PF. Expression of vascular endothelial growth factor by human eosinophils: upregulation by granulocyte macrophage colony-stimulating factor and interleukin-5. Am J Respir Cell Mol Biol 1997; 17: 70-77.

16. Tazelaar HD, Linz LJ, Colby TV, Myers JL, Limper AH. Acute eosinophilic pneumonia: histopathologic findings in nine patients. Am J Respir Crit Care Med 1997; 155: 269302.

17. Allen JN, Liao Z, Wewers MD, Altenberger EA, Moore SA Allen ED. Detection of IL-5 and IL-1 receptor antagonists in bronchoalveolar lavage fluid in acute eosinophilic pneumonia. J Allergy Clin Immunol 1996; 97: 1366-1374.

18. Kay AB. "Helper" (CD4+) T cells and eosinophils in allergy and asthma. Am Rev Respir Dis 1992; 145: S22-S26.

19. Martin LB, Kita H, Leiferman KM, Gleich GJ. Eosinophils in allergy: roles in disease, degranulation, and cytokines. Int Arch Allergy Immunol 1996; 109: 207-215.

20. Weller PF. The immunology of eosinophils. N Engl J Med 1991; 324: 1110-1118.

21. Moqbel R, Levi-Schaffer F, Kay AB. Cytokine generation by eosinophils. J Allergy Clin Immunol 1994; 94: 1183-1188.

22. Tischer E, Mitchell R, Hartman T, et al. The human gene for vascular endothelial growth factor. Multiple protein forms are encoded through alternative exon splicing. $J$ Biol Chem 1991; 266: 11947-11954.

23. Iijima $\mathrm{K}$, Yoshikawa $\mathrm{N}$, Connolly DT, Nakamura $\mathrm{H}$. Human mesangial cells and peripheral blood mononuclear cells produce vascular permeability factor. Kidney Int 1993; 44: 959-966.

24. Effros RM, Mason GR, Hukkanen J, Silverman P. New evidence for active sodium transport from fluid-filled rat lungs. J Appl Physiol 1989; 66: 906-919.

25. Kim KJ, Crandall ED. Specialized alveolar epithelial transport processes. In: Effros RM, Chang K, eds. Fluid and Solute Transport in the Airspace of the Lungs. New York, Marcel Dekker, 1994; pp. 219-248.

26. Staub NC, Nagano H, Pearce ML. Pulmonary edema in dogs, especially the sequence of fluid accumulation in lungs. J Appl Physiol 1967; 22: 227-240.

27. Flick MR. Pulmonary edema and acute lung injury. In: Murray JF, Nadel JF, eds. Textbook of Respiratory Medicine. Philadelphia, WB Saunders Company, 1994; pp. $1725-1777$.

28. Guyton AC, Lindsey AW. Effect of elevated atrial pressure and decreased plasma protein concentration on the development of pulmonary edema. Circ Res 1959; 7: 649-657.

29. Kaner RJ, Ladetto JV, Singh R, Fukuda N, Matthay MA Crystal RG. Lung overexpression of the vascular endothelial growth factor gene induces pulmonary edema. Am J Respir Cell Mol Biol 2000; 22: 657-664.

30. Mori A, Suko M, Nishizaki Y, et al. Interleukin-5 production by CD4+ T cells of asthmatic patients is suppressed by glucocorticoids and immunosuppressants FK506 and cyclosporine A. Int Immunol 1995; 7: 449-457.

31. Mori A, Kaminuma O, Suko M, et al. Two distinct pathways of interleukin-5 synthesis in allergen-specific human T-cell clones are suppressed by glucocorticoids. Blood 1997; 89: 2891-2900. 